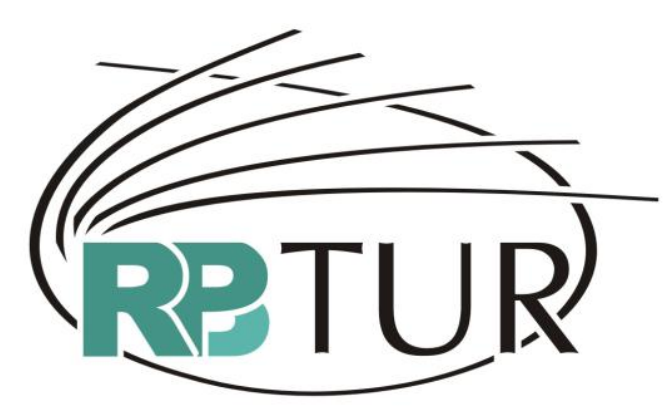

REVISTA BRASILEIRA DE PESQUISA EM TURISMO

\title{
CONTRIBUIÇÕES DA NOVA GEOGRAFIA CULTURAL NA ATIVIDADE TURÍSTICA
}

\section{CONTRIBUTION OF THE NEW CULTURAL GEOGRAPHY ON TOURISM ACTIVITIES}

\section{LAS CONTRIBUICIONES DE LA NUEVA GEOGRAFIA CULTURAL EN LA ACTIVIDAD TURÍSTICA}

Daniela Sottili Garcia ${ }^{1}$

Miguel Bahl

\begin{abstract}
Resumo: Este artigo foi desenvolvido tendo como foco de estudo a contribuição da "Nova Geografia Cultural" para a atividade turística, trazendo como exemplo o desenvolvimento do setor de Turismo na cidade de Campo Grande (Mato Grosso do Sul, Brasil) e a análise de como este setor tem utilizado a cultura local como marca urbana. Utilizou-se como metodologia um levantamento bibliográfico sobre a vertente da "Nova Geografia Cultural" e da atividade turística, e posteriormente a análise de situação da mesma nesta cidade. Apontam-se como resultados que esta vertente geográfica iniciada no mundo por volta de 1960 e no Brasil em 1970, tem contribuído, sobremaneira, para diversos campos de estudo, como é o caso específico do turismo, principalmente por inserir em seus estudos o homem como agente principal, passando a considerá-lo como primordial e parte integrante do processo de desenvolvimento dos espaços.
\end{abstract}

Palavras-chave: Turismo. Cultura. Nova Geografia Cultural. Campo Grande. Brasil.

Abstract: This article was developed having as major field of study the contribution of New Cultural Geography to the touristy activity, getting as example the development of the touristy sector at the Campo Grande city (Mato Grosso do Sul, Brazil) and the analysis of how this sector has been trying to utilize the local culture as urban brand.

1 Bacharel em Turismo (UCDB), Especialista em Gestão de Turismo, Hotelaria e Eventos, Mestre em Geografia (UFMS), Doutoranda em Geografia (UFPR). Professora Efetiva do Curso de Turismo da Universidade Estadual de Mato Grosso do Sul (UEMS), Bolsista FUNDECT. Email: sottili@uems.br

2 Bacharel em Turismo, Licenciado em Estudos Sociais e em Geografia (UFPR), Mestre e Doutor em Ciências da Comunicação (USP). Professor classe titular do Curso de Graduação em Turismo e no Programa de Pós-Graduação Mestrado e Doutorado em Geografia (UFPR). Email: migbahl@ufpr.br 
It was used as metodology a bibliographic survey about a field of the "New Cultural Geography" and the touristy activity, and later the analysis of the touristy activity situation at this city. It is appointed like results that this geographic field that started in the world around 1960 and in Brasil in 1970, has been contributed, to some extent, to sundries fields of study, like it is the specific case of the tourysm, specially by this field to insert in its studies the man, considering him as overriding and component part of the space development process.

Keywords: Tourism. Culture. New Cultural Geography. Campo Grande. Brazil.

Resumen: En este trabajo se discute el turismo comunitario en áreas rurales como actividad que transforma y modifica personas y ambientes, ya que se trata de un área que atraviesa el contexto y las vidas en sus más diversas dimensiones. Analizamos esta realidad a partir de las intersecciones y diferencias entre los discursos producidos en dos investigaciones realizadas en los últimos dos años. Cada una, a partir de una mirada distinta (la primera desde el discurso académico y la segunda desde los discursos mediáticos) sobre el mismo fenómeno, presente ejes diferentes de evaluación de las percepciones que los sujetos tienen de una misma situación. Para la elaboración de este artículo se dieron los siguientes pasos metodológicos: lectura de los resultados de cada investigación, selección de los discursos considerando las categorías de análisis convergentes y divergentes y finalmente el análisis conjunto de los datos y la discusión de los mismos. Notamos la existencia de dos discursos, con un formato o una imagen desvirtuada del turismo, capaces o de crear expectativas desnecesarias o de desalentar otras, lo que puede ser igualmente perjudicial a las propuestas futuras de crecimiento de la actividad turística en la región.

Palabras clave: Turismo. Cultura. Nueva Geografia Cultural. Campo Grande. Brasil.

\section{Introdução}

Neste artigo se faz uma discussão da importância da cultura no campo da Geografia e do Turismo, sobretudo, a respeito da importância da Nova Geografia Cultural para o desenvolvimento da atividade turística.

A Nova Geografia Cultural não é uma escola, assim como, por exemplo, a do Marxismo, mas trata-se de uma vertente consideravelmente recente, que foi introduzida cientificamente no mundo por volta da década de 1960 e no Brasil, uma década mais tarde, por volta de 1970, na Universidade Estadual de São Paulo (UNESP), unidade de Rio Claro. Com estudos direcionados para a inserção do homem no contexto do espaço ressurgem duas décadas mais tarde (em 1990) na Universidade Estadual do Rio de Janeiro. Atualmente a Nova Geografia Cultural tem recebido grandes contribuições de estudos de diversas áreas em todo o Brasil, e também muito tem contribuído para outras áreas. 
A principal característica da Nova Geografia Cultural é a de inserir o homem em seus estudos, entendendo que ele tem papel fundamental no desenvolvimento de todo o processo (CLAVAL, 2001).

Neste contexto, discute-se, neste artigo, a importância da compreensão e da inserção do homem nos estudos do espaço pelos geógrafos. Ainda neste processo, surgem as atividades turísticas que dependem da compreensão do homem no espaço para seu desenvolvimento. Para tanto, é intenção deste artigo discutir a relação da atividade turística na Nova Geografia Cultural e compreender a relação do homem com o espaço turístico.

Assim sendo, inicia-se explicando o surgimento da Nova Geografia Cultural, seus pontos positivos e negativos; posteriormente, traz a inserção dos estudos turísticos nesta nova vertente, e por último, apresenta como exemplo a inserção da atividade turística no espaço urbano da cidade de Campo Grande (Mato Grosso do Sul, Brasil), sendo a mesma analisada e estudada na perspectiva da Nova Geografia Cultural, onde o homem é parte integrante do processo de desenvolvimento dos espaços, e neste caso específico, do espaço turístico.

\section{A Nova Geografia Cultural}

Na tentativa de entender e discutir a Nova Geografia Cultural julga-se necessário, primeiramente, compreender onde, como e por que ela surge nos estudos geográficos, pois é sobre o espaço que o homem constrói seu cotidiano e consequentemente apresenta sua cultura.

Os estudos da Nova Geografia Cultural surgem principalmente para compreender como a vida dos indivíduos e dos grupos se organiza no espaço, e ainda entender por que os indivíduos e os grupos não vivem os lugares do mesmo modo, não os percebem da mesma maneira (CLAVAL, 2001).

A mudança do foco se deu principalmente porque uma das principais críticas que existia sobre a Geografia Cultural é a de que ela preocupava-se muito mais em descrever o mundo do que em compreendê-lo ou explicá-lo. 
Por isso surge a Nova Geografia Cultural com o objetivo de se preocupar muito mais em entender como os homens modelam os ambientes e desenham as paisagens do que simplesmente descrever o mundo (CLAVAL, 2001). O mesmo autor discorre que a Nova Geografia Cultural busca entender a maneira como as pessoas vivem sobre a Terra; elas fazem a experiência dos lugares que habitam ou visitam, encontram indivíduos e grupos, dão um sentido a esses contatos e tentam modificar as realidades nas quais vivem.

Desde o início da década de 1970, a Nova Geografia Cultural foi cada vez mais associada à exploração de temáticas humanas mais específicas, tais como: a dos negros, dos índios, das mulheres, das minorias étnicas ou de gêneros sexuais, de grupos religiosos, de populações marginais, dentre outras. Os geógrafos que hoje trabalham com a Nova Geografia Cultural exploram categorias ignoradas pela maioria dos seus predecessores, como é o caso dos estudos sobre turismo, tema do qual este artigo tratará.

A abordagem cultural não está limitada àquilo que há meio século era classificado sob o rótulo de "Geografia Cultural". Seu campo é muito maior, por conscientizar os geógrafos de que suas atividades fazem parte da esfera cultural e que é possível construir uma abordagem científica livre de determinação cultural (CLAVAL, 2001).

Ainda sobre a Nova Geografia Cultural, baseando-se nos ditos do autor acima, podem-se apresentar algumas de suas características: explora a experiência vivida das pessoas, seus sonhos, aspirações e desejos; descreve a diversidade de comportamentos e atitudes com relação ao meio ambiente, à natureza e à vida social, econômica e política. Mostra ainda as numerosas tensões que resultam da diversidade dos projetos que formam os homens, cada grupo lutando para garantir recursos que muitas vezes são raros.

Para essa "Nova" Geografia a cultura não é uma categoria residual, mas o meio pelo qual a mudança social é experienciada, contestada e constituída (COSGROVE; JACKSON, 2003, p.136). Mas nem por isso a Nova Geografia Cultural deixa de apresentar lacunas em suas abordagens, porque todas as temáticas anteriormente citadas são verdadeiras, mas, em decorrência do 
paradigma sobre o qual repousa a abordagem cultural, parece impossível construir um sistema coerente de interpretação a partir de descrições "densas" e de estudos de casos verdadeiros que surgiram há trinta anos.

A nova abordagem cultural permite restituir coerência à disciplina sem sair de uma perspectiva relativista; certa previsibilidade nas condutas sociais é introduzida pela experiência da comunicação.

Também se faz válido ressaltar que muitos dos estímulos para a Nova Geografia Cultural vieram de convergência teórica e metodológica entre disciplinas humanísticas, como a História, a Filosofia, Estudos Linguísticos e das Ciências Sociais, as quais sustentam o amplo campo dos estudos culturais (COSGROVE, 1999).

Um dos grandes focos da Nova Geografia Cultural é o estudo da cultura, e nesse aspecto, dentro da categoria de cultura alternativa, Cosgrove (2004) diferenciou:

- Cultura residual (culturas históricas que desapareceram ou estão em processo de extinção);

- Culturas emergentes (aquelas que só agora estão aparecendo), e

- Culturas excluídas (aquelas que são ativa ou passivamente excluídas pela cultura dominante).

Cada indivíduo é portador de um sistema cultural em evolução constante, mas que é estruturado pelos valores. Estes são adquiridos pelos indivíduos no decorrer de sua trajetória de vida, ao sabor dos ensinamentos que receberam e das experiências que têm (CLAVAL, 1999, p.72).

Para tanto, pode-se afirmar que na construção de sistemas individuais de cultura é em termos de níveis de valores que a parte coletiva se sobrepõe à individual.

Graças ao jogo de valores, aos procedimentos sociais de institucionalização e aos ritos de passagem é que as culturas individuais se acham integradas nos sistemas simbólicos, dando sentido à vida de cada indivíduo e constituindo o coletivo. Nesse sentido a cultura não é uma 
realidade primeira, mas uma construção imaginada que permite que as pessoas se comuniquem e formem grupos unidos (CLAVAL, 1999).

Inseridos nos estudos da Nova Geografia Cultural, cabem também os estudos turísticos, que têm sido contemplados com as pesquisas desta nova vertente e a cultura tem se tornado elemento fomentador de inúmeras atividades turísticas, principalmente nos espaços urbanos, onde possuem uma melhor infra-estrutura para acolher os turistas.

\section{Os Estudos Turísticos Inseridos na Nova Geografia Cultural}

O número de estudos turísticos tem crescido significativamente, tanto em termos de quantidade como também de qualidade; isso se dá em grande parte pela contribuição da Nova Geografia Cultural em suas pesquisas.

No âmbito destes estudos, atualmente, torna-se inconcebível estudar a geografia de uma cidade, de uma região, ou ainda de um país, sem se interessar pelas pessoas que nela vivem. Neste contexto, para um melhor entendimento das transformações das cidades ao longo do tempo, a discussão e o entendimento de espaço urbano se fazem necessários neste trabalho, na expectativa de não se considerá-lo apenas como palco ou como um mero pano de fundo para os acontecimentos urbanos, mas, sobretudo sendo o grande propulsor e fomentador para os acontecimentos de ordem política, econômica e cultural no desenvolvimento das cidades.

Entende-se o espaço urbano como reflexo e condicionante da sociedade urbana, de maneira que a interação do homem com o espaço urbano, ao longo do tempo, forme também um espaço cultural.

O espaço urbano capitalista - fragmentado, articulado, reflexo, condicionante social, cheio de símbolos e campos de lutas - é um produto social, resultado de ações acumuladas ao longo do tempo, e engendradas por agentes que produzem e consomem 0 espaço (CORREAA; ROSENDHAL, 1989, p.11). 
A fragmentação do espaço urbano se dá pelos seus diferentes usos, como os de comércio, de lazer e de indústria. Já a articulação manifesta-se mais ou menos visível, de acordo com as ações do homem (CORRÊA; ROSENDAHL, 1989).

Os citadinos fazem parte da visão que se tem de uma cidade, já que são eles que contribuem para com a produção do espaço urbano, fazendo-o singular. As suas ações criam "marcas urbanas", que são os sinais e signos incorporados à paisagem (CASTROGIOVANNI, 2000).

Como já anunciado, parte da proposta deste artigo se propõe apresentar como a atividade turística está sendo desenvolvida no espaço urbano de Campo Grande (Mato Grosso do Sul). Diante disto, entende-se necessário apresentar alguns aspectos desta cidade, para posterior entendimento da inserção do turismo neste contexto.

\section{Conhecendo a História de Campo Grande}

O município de Campo Grande foi criado no dia 26 de agosto de 1899, pela Lei estadual no. $225^{3}$. Ele possuía uma área superior a $100.000 \mathrm{~km}^{2}$, abrangendo os atuais municípios de Rio Brilhante, Nova Alvorada do Sul, Bataguassu, Ribas do Rio Pardo, Rochedo, Terenos, Sidrolândia, Jaraguari e Camapuã (SALGADO, 2001). Atualmente, Campo Grande possui uma área total de $8.092,97 \mathrm{~km}^{2}$ e uma área urbana de $154,45 \mathrm{~km}^{2}$, conforme o Instituto Brasileiro de Geografia e Estatística (IBGE, 2011).

Campo Grande foi colonizada por migrantes que vieram aproveitar os campos de pastagens nativas e as águas cristalinas da região dos cerrados. A cidade foi planejada em meio a uma vasta área verde, com ruas e avenidas largas. Relativamente arborizada e com diversos jardins por entre as suas vias, ainda possui forte relação com a cultura indígena e suas raízes históricas. Por

\footnotetext{
${ }^{3}$ No ano de 1977, o então Estado de Mato Grosso foi dividido em dois estados pela Lei Federal Complementar $n^{\circ}$. 31, criando na parte sul do então Mato Grosso o novo Estado de Mato Grosso do Sul (MS), e na parte norte permaneceu como Estado de Mato Grosso (MT). O Estado de Mato Grosso do Sul ficou tendo como capital a cidade de Campo Grande, sendo instalado oficialmente em 1979.
} 
causa da cor de sua terra (roxa ou vermelha), recebeu a alcunha de Cidade Morena.

Está localizada em região de planalto no centro do Estado de Mato Grosso do Sul e equidistante dos seus extremos norte, sul, leste e oeste, fator que facilitou a construção das primeiras estradas da região, contribuindo para que se tornasse a grande encruzilhada ou polo de desenvolvimento de uma vasta área.

De acordo com Salgado (2001) o crescimento e desenvolvimento de Campo Grande também se deve à miscigenação de muitas nacionalidades que na cidade vieram buscar novas oportunidades de trabalho, dentre elas: paraguaios e bolivianos, estes contribuiram sobremaneira no desenvolvimento inicial da pecuária no município e os japoneses que foram atraídos pela construção da ferrovia que cortava o então estado de Mato Grosso e cruzava a cidade, eles contribuiram para a culinária da cidade trazendo sua cultura, como por exemplo o sobá - prato típico japonês que tem como base um macarrão feito artesanalmente e um caldo especial que obriga o indivíduo a comer em uma cumbuca. Este prato é tão relevante na culinária local que inclusive foi criado o Festival do Sobá (já em sua quinta edição), que acontece anualmente na Feira Central de Campo Grande.

Ainda se encontram outros grupos, entre eles: os libaneses que sairam de seus países por causa das guerras e chegaram a Campo Grande pela estrada de ferro; além dos portugueses, italianos, espanhóis, sírios, árabes, armênios, turcos, poloneses, palestinos, gregos, bem como, de brasileiros de diversas procedências: mineiros, paulistas, paranaenses (SALGADO, 2001).

A partir disso, pode-se constatar a existência de uma diversidade de influências culturais oriundas de estrangeiros e brasileiros de diversas conotações: brancos, negros, índios e caboclos, entre outros.

Esta cidade teve o seu início num aglomerado de casas rústicas que pontilhavam nas margens dos córregos Prosa e Segredo. Atualmente, Campo Grande, capital de Mato Grosso do Sul, é uma cidade com 787.204 mil 
habitantes ${ }^{4}$, localizada geograficamente na porção central do Estado. É a cidade mais populosa do Estado, o que contribui para que ofereça uma melhor infra-estrutura urbana e turística. Pela sua posição geográfica e por ser a capital do estado onde está localizada a maior parte do Pantanal, Campo Grande tornou-se passagem obrigatória para os turistas que se destinam àquela região. Aproveitando-se disso, o trade ${ }^{5}$ turístico criou para a cidade uma imagem relacionada com motivos de forte apelo pantaneiro. Essa realidade, por muitas vezes, tem distorcido ou ainda ignorado a sua verdadeira identidade.

Assim como outras cidades, ela passou e ainda passa por ações de agentes sociais que incluem mudanças na sua produção sócio-espacial, fato que tem ocasionado interpretações diferentes pelos citadinos.

Devido ao fato de a cidade concentrar espacialmente os equipamentos e a estrutura necessários ao desenvolvimento do turismo de massa, que é a infra-estrutura de acesso, de hospedagem, de apoio à atividade e de lazer, e devido, ainda ao fato de ela, por si só, se constituir num atrativo turístico, é que o turismo urbano representa a quase totalidade dos seus fluxos turísticos, alinhando-se ao que comenta Cruz (2001) que afirma que o turismo ocorre principalmente nos centros urbanos.

A cidade de Campo Grande foi fundada em 26 de agosto de 1899, portanto, completou 111 anos de existência. Ao longo desses anos, construiu uma história e uma cultura próprias, que aparentemente não são valorizadas na construção da imagem que lhe atribuem como destino turístico.

Percebe-se na cidade a globalização cultural sob a vertente de diluir suas características. Este fato pode ser considerado como prejudicial para a atividade turística que tem incorporado, ao longo dos anos, turistas buscando conhecer o diferente, o inusitado, de forma que o ideal seria evidenciar as especificidades da cidade.

\footnotetext{
${ }^{4}$ Informações obtidas pelo site do IBGE no dia 23 de fevereiro de 2011 , às $14 \mathrm{~h} 29 \mathrm{~m}$, de acordo com o censo 2010.

5 Por trade turístico entendem-se as empresas públicas e privadas locais que gerenciam a atividade turística.
} 
Segundo SANTOS (2005, p.145) "podemos, pois, admitir que a globalização constitua um paradigma para a compreensão de diferentes aspectos da realidade contemporânea". Mas, se por um lado ela aparenta levar o mundo ao alcance de todos, por outro lado, pois, aparentemente a ordem local perde sua força perante a global. Porém, o importante mesmo é que os locais permaneçam e fortaleçam suas características e peculiaridades.

Nesse sentido, para atenuar os efeitos da globalização no caso da cidade de Campo Grande, deve-se estimular a propagação da sua cultura local, atraindo novos turistas dispostos a conhecer as reais especificidades culturais desta capital sul-matogrossense.

\section{A Cidade de Campo Grande e a Atividade Turística}

Uma cidade é um mundo de representações. Por meio das pessoas que nela residam, possui vida e constitui uma identidade que lhe é própria. Neste contexto, Campo Grande deve pleitear sua condição de cidade turística com sua própria história - "marca urbana".

Essas ações proporcionam uma forma, um lugar, e a idéia de lugar: "consiste da extensão do acontecer homogêneo ou do acontecer solidário, a partir de duas construções: a configuração territorial e a norma, mesmo que efêmera" (SANTOS, 1994, p.36). Nesse sentido, a cidade de Campo Grande precisa trazer e evidenciar suas características que a tornam um lugar.

O lugar deve ser entendido como toda a sociedade, constituindo-se de fatos e situações que definem o cotidiano. Quanto mais inserido na mundialidade, mais apartado da história ele se torna, afirmação esta que aponta o risco de os lugares buscarem o simulacro e o quão é importante valorizar as especificidades locais.

Ainda nesse sentido, é válido fazer considerações sobre o termo lugar, pois "o lugar" de acordo com o respaldo de alguns autores, iniciando-se por Milton Santos consiste em: 
O lugar é a oportunidade do evento. E este, ao se tornar espaço, ainda que não perca suas marcas de origem, ganha características locais. É como se a flecha do tempo se entortasse no contacto com o lugar. O evento é, ao mesmo tempo, deformante e deformado. Por isso, fala-se na imprevisibilidade do evento, a que Ricoeur chama de autonomia, a possibilidade, no lugar, de construir uma história das ações que seja diferente dos projetos dos atores homogênicos. É esse o grande papel do lugar na produção da História e apontá-lo é a grande tarefa dos geógrafos neste fim de século (SANTOS, 1994 apud GOMES, 2003, p.486).

Para Damiani (2005, p.169), "a vida cotidiana, o lugar do simples e do sórdido, é, simultaneamente, o lugar e no tempo em que o humano se realiza".

Existem duas formas de o local se definir; de dentro ou de fora, no primeiro ele utiliza sua própria identidade, já no de fora ele deixa de possuir um caráter próprio (GOMES, 2003). Para as cidades que buscam se desenvolver no setor turístico, o ideal é que elas se divulguem de dentro para fora, ou seja, que levem em conta suas particularidades.

Os lugares são ligados pela informação e acabam tendo um papel fundamental no espaço, como se eles fossem desamarrar o "nó" existente na sociedade, por conta das desigualdades nele vivenciadas.

Mas o primordial sobre lugar é entender o todo e o particular como uma totalidade dialética e passível de transformação. No caso dos espaços urbanos, é importante que uma cidade possua identidade própria e que, sobretudo, tenha conseguido construir um lugar dentro de seu espaço, algo que se destaque e possa ser reconhecido. Esse lugar deve possuir um significado para a construção daquela cidade.

O significado e a importância dos lugares variam por diversos fatores, como a história, as condições existentes no momento da internalização e o jogo de relações que se estabelecem entre o que chega e o que já existe. É este conjunto de "coisas" que contribui para que os resultados sejam diferentes, particulares, segundo os lugares.

A configuração espacial de um lugar deve passar por um estudo aprofundado, desde o homem até o das instituições que vão dirigir (SANTOS, 1997). 
Os lugares são também perceptíveis nas paisagens que, sendo uma unidade conceitual da Geografia, podem ser definidos como áreas compostas por associação distinta de formas ao mesmo tempo físicas e culturais.

Paisagem é tudo aquilo que vemos, o que nossa visão alcança, é a paisagem. Esta pode ser definida como o domínio do visível, aquilo que a vista abarca. Não é formada apenas de volumes, mas também de cores, movimentos, odores, sons etc. (SANTOS, 1997, p.61).

SAUER (1925) explica "a paisagem geográfica como sendo o resultado da ação cultural, ao longo do tempo, sobre a paisagem natural" e que por isso ela apresenta uma dimensão histórica e é portadora de significados que expressam valores, crenças, mitos e utopias, caracterizando assim uma dimensão simbólica entendida, desta forma, como paisagem cultural.

A paisagem cultural seria, então, a transformação da paisagem natural, onde a cultura seria o agente, a área natural o meio e a paisagem cultural o resultado (SAUER, 1925). Carlos (2007) confirma isso quando diz que a paisagem está sempre em transformação.

A paisagem é plurimodal ativa, passiva, potencial etc.. Para isso, Cosgrove (2003) identifica dois tipos de paisagens geográficas: a paisagem da cultura dominante, onde o grupo dominante exerce seu poder, e as paisagens alternativas, que são as residuais, emergentes e excluídas.

Para o entendimento de como Campo Grande se apresenta enquanto cidade turística é importante analisar quais desses tipos de paisagens são aplicados a ela.

Entende-se que "a paisagem tem uma identidade que é baseada na constituição reconhecível, limites e relações genéricas com outras paisagens, que constituem um sistema geral" (CORRÊA; ROSENDAHL, 2004, p.23). Dessa maneira, pode-se trabalhar com o fato de que a paisagem não é simplesmente uma cena real, mas sim uma cena observada por partes individuais que constituem o todo. Além desse fato, toda paisagem possui uma relação com outras paisagens, nenhuma é réplica de outra, pois são levadas em 
consideração as percepções, o que as fazem diferir das demais pelo entendimento individual do observador.

No caso das cidades que buscam a construção de uma imagem semelhante à de outras já existentes, elas correm dois riscos: um é o fato de se tornarem conhecidas apenas pela semelhança com as outras, sem demonstrar as suas imagens com seus valores históricos, e sem serem lembradas pelos seus próprios potenciais; o outro é o fato de o visitante interpretar como sendo um potencial artificial, sem significativos potenciais turísticos, e consequentemente, sem valores individuais da especificidade cultural, uma vez que elas se submetem aos julgamentos individuais.

A paisagem possui um conteúdo, mas este é menor do que a totalidade, ele é constituído por partes. Sendo assim, a identidade da paisagem é determinada pela visibilidade da forma, porque o conteúdo aqui mencionado é determinado por interesses e julgamentos pessoais (CORRÊA; ROSENDAHL 2004).

A paisagem é dividida em duas metades. A primeira recebe a designação de sítio e a segunda metade, que vem ao encontro aos interesses aqui propostos, é vista como uma unidade bilateral e que apresenta sua expressão cultural. Vale ressaltar que se busca abordar aqui o tema cultura como uma expressão geográfica, de maneira que não há lugar para o dualismo da paisagem (CORRÊA; ROSENDAHL, 2004).

Então, não se pode pensar em paisagem se não associada ao tempo, com suas relações vinculadas ao espaço, o que contribui para que as ações do homem constituam a paisagem cultural, uma vez que ele vai expressando seu lugar na natureza como um agente distinto de modificação. A paisagem cultural é, pois, então sujeita a mudanças pelo desenvolvimento da cultura ou pela sua substituição (CORRÊA; ROSENDAHL, 2004).

Nesse contexto

A paisagem cultural é a área geográfica em seu último significado. Suas formas são todas as obras do homem que caracterizam a paisagem. Com base nesta definição, em geografia não nos preocupamos com a 
Isso de maneira alguma significa que a paisagem natural não tenha sua importância, pois é ela que fornece materiais com os quais a paisagem cultural é formada. "Ao contrário da maioria das Ciências Sociais, a Geografia Cultural sempre levará cuidadosamente em conta o material físico do qual cada cultura imprime a marca que lhe é própria - marca que ela considera como uma geografia [...]" (CORRÊA; ROSENDAHL, 2004).

Diante disso, entende-se que a paisagem natural tem um papel fundamental no processo de construção da paisagem cultural para a formação da identidade, sendo a própria cultura a modeladora dessa paisagem.

É válido, porém, ressaltar que quando acima foi citado que não são as crenças, os costumes e a energia levados em conta, não se teve a intenção de desmerecê-los, uma vez que são eles que compõem ou contribuem com a construção da identidade de uma cidade.

Isso contribui para uma reflexão sobre Campo Grande, uma vez que ela possui uma cultura evidenciada capaz de modelar uma identidade local, transformando-a em destino turístico. Por meio de sua história, é possível identificar na cidade uma cultura relacionada à pecuária, desde seus primórdios e mais recentemente surgindo também o setor econômico relacionado a eventos.

Corrêa e Rosendahl (2004) advertem que

\begin{abstract}
A paisagem é uma marca, pois, expressa uma civilização, mas também é uma matriz porque participa dos esquemas de percepção, de concepção e de ação - ou seja, de cultura - que canalizam, em um certo sentido, a relação da sociedade com o espaço e com a natureza e, portanto, a paisagem do seu ecúmeno. E assim, sucessivamente, por infinitos laços de co-determinação (CORRÊA; ROSENDAHL, 2004, p. 85) (grifo dos autores).
\end{abstract}

São consideráveis as interrogações feitas por Corrêa e Rosendahl (2004), quando questionam: de que forma a paisagem imposta é sentida e, eventualmente, interpretada? Como se pode projetar nela um imaginário? 
A geografia não se limita à observação e à descrição do visível, de maneira que o imaginário entra em cena sempre que a atividade turística é idealizada para uma futura realização.

A sociedade organiza, transforma e, em certos casos, escolhe seu meio ambiente graças a técnicas de enquadramento que são, segundo $P$. Gourou, a expressão de uma "civilização". Por outro lado, a "cultura" contribui para a interpretação do espaço, permite a articulação entre o imaginário e as "coisas do real" (CORRÊA; ROSENDAHL, 2004, p. 89) (grifo dos autores).

Assim, o significado de uma propriedade ou de uma função em uma paisagem geográfica varia. Alguns fatores contribuem para isso, por exemplo, quanto maior for a dimensão do objeto, maior será seu entendimento. Para uma compreensão mais real se fazem necessárias informações do meio que rodeia e compõe a paisagem. Para tanto, é relevante o observador ter conhecimento do todo, da história da cidade, para compreender melhor os lugares que compõem o todo - a cidade.

De fato, a autonomia dos indivíduos é limitada por sua vinculação a grupos, o que leva, em alguns casos, a formação da paisagem a ter características apenas da elite política e econômica de determinada cidade.

A percepção construída pelo citadino consiste em concentrar o que ele conhece sobre a sua cidade, mas é válido ressaltar que sendo ele o sujeito deste processo, ele pode ter informações totais ou parciais, o que contribui para a construção da imagem turística da cidade, que pode ou não estar relacionada com a realidade.

A cultura pode influenciar a percepção de tal maneira que as pessoas podem ver coisas que não existem, a comunidade local pode vir a identificar e divulgar uma imagem que não há, ou ainda, que não seja a mais apropriada. Isso se dá pelo envolvimento dela com a cidade, não se dando a oportunidade de analisar a cidade sem interferências políticas ou comerciais.

Resultado do homem na sociedade capitalista é o homem-peça da cidade-máquina, máquina de fazer réplicas, fato este ocorrido nos últimos anos 
sobre as cidades turísticas, sendo consequência a construção, tanto pelo poder público como pelo privado, de réplicas de locais turísticos.

$\mathrm{Na}$ maioria das vezes, por estarem envolvidos no processo de desenvolvimento da cidade os citadinos, passam a não perceber as particularidades de suas cidades, as quais seriam muito mais atraentes aos olhos do turista do que meramente a construção de simulacros de outras cidades, muitas vezes já consolidadas como destinos turísticos.

Mas é fato também que as réplicas nem sempre agradam aos olhos, aos desejos e sonhos de quem as compra - os turistas -, o que acaba contribuindo na insatisfação turística e no baixo sucesso dos destinos turísticos, porque o que realmente atrai os turistas é o inusitado, as especificidades de cada cidade.

Cabe aqui considerar que, para os núcleos turísticos, o ideal é a paisagem constituída pela cultura dominante, desde que proporcione espaço para as manifestações culturais e interesses de sua comunidade como um todo.

A cidade pode ser analisada por diferentes formas, e uma delas é a cultural, que ganhou maior destaque no campo científico a partir da década de 1960. "E a cultura resulta da capacidade dos seres humanos se comunicarem entre si por meio de símbolos" (WAGNER; MIKESELL, 2003, p.28).

No caso de Campo Grande, frequentemente, moradores e turistas ficam surpreendidos quando indagados sobre qual seria a identidade cultural da cidade, pois não conseguem definir claramente a identidade local.

Nesse sentido se fazem necessários estudos que permitam refletir sobre aspectos sociais e culturais da população campo-grandense e, consequentemente, sobre a sua identidade. É importante lembrar que os agentes sociais que fazem e refazem a cidade não podem perder suas raízes culturais.

Para tanto, o papel da cultura neste processo é ímpar: 
GARCIA, Daniela Sottilli; BAHL, Miguel. As contribuições da Nova Geografia Cultural na atividade turística. Revista Brasileira de Pesquisa em Turismo. v.5, n.1, p.23-44, abr. 2011.

resultado de uma construção intelectual, derivada de tradição étnica cujos traços são permanentemente recriados. Essa identidade cultural do lugar, reconhecida tanto interna quanto externamente (RELPH, 1976), expressa-se em vários aspectos relativos à sua organização social, política e espacial. No entanto, pode ser objeto de contestação, por meio de práticas políticas que introduzem novos significados ao lugar, criando um confronto identitário (CORRÊA, 2006, p. 148).

A problemática se estabelece na medida em que emergem cidades que desempenham o papel de transformação cultural, constituindo outras cidades, alterando o mapa cultural e contribuindo para que essas cidades fiquem sem suas "marcas urbanas".

A globalização da cultura possibilitou a Hannerz (apud CORRÊA; ROSENDAHL, 2006) elaborar o conceito creole culture. Para este autor, este conceito envolve a diversidade, interconectividade e inovação, gerando inovações mercantilizadas. Segundo este autor, a diversidade refere-se à confluência recente de tradições culturais histórica e geograficamente distintas, e a interconectividade seriam as interações permanentes entre significado e formas simbólicas, gerando inovações mercantilizadas. Adaptando esta expressão a cidades que buscam desenvolver uma imagem turística, pode-se entender que o ideal seria trabalhar sua imagem turística vinculada diretamente à sua identidade cultural; contudo, poderia ser trabalhada paralelamente a forma mais apropriada para comercialização desta cidade sem perder o foco de suas raízes culturais (CORRÊA, 2006).

A globalização cultural tem duas vertentes, uma é a de reforçar algumas características locais e a outra consiste em diluir determinadas características (CORRÊA, 2006).

Sob essa ótica, a cidade de Campo Grande se desenvolve em direção à segunda vertente ora apresentada, que, do ponto de vista turístico, é a menos favorável para seu desenvolvimento e seu sucesso enquanto destino turístico.

A "marca urbana" é a identidade da cidade; é ela que redefine as relações entre as pessoas, grupos, lugares, coisas, porém historicamente ela está muito mais voltada à ideologia, remetendo-a a ambiguidade. A questão do tempo colabora para o esquecimento de algumas ações que contribuíram para 
a construção identitária da cidade, prevalecendo o campo econômico como fator de maior importância (YÁZIGI, 2002).

Uma pesquisa desenvolvida por SOTTILI (2005) apontou que os agentes sociais de Campo Grande divulgam a imagem turística da cidade associada à do Pantanal, deixando assim, de divulgar as especificidades locais, como por exemplo, a forte relação da cidade com a pecuária e com o turismo de eventos.

Campo Grande é uma cidade que possui potencial próprio para o desenvolvimento turístico por meio de seus inúmeros atrativos turísticos, dentre os quais, pode-se destacar: Feira Central, Parque das Nações Indígenas, Morada dos Baís, Mercado Municipal, city tour, entre outros. Dentre eles, destaca-se o city tour que leva os turistas a quarenta e cinco pontos turísticos da cidade: em dois deles (Memorial da Cultura Indígena e Museu do Índio) há uma parada para visitação; os demais são apenas visualizados durante o percurso e o guia de turismo conta a historia de cada um desses atrativos.

As cidades parecem estar em um concurso, disputando quem chega mais próximo da imitação perfeita. Por hora, talvez isso resolva em termos de número de turistas recebidos e divisas deixadas no receptivo, mas com o passar do tempo, com a diversidade de destinos turísticos cada vez maiores, os turistas optarão por aqueles que se destacarem por suas especificidades e que ultrapassarem a única barreira até então desejada, que é a econômica.

Em dado momento, a imagem urbana representa a cidade e a ela somase a percepção, dela busca-se extrair informações capazes de formar uma imagem representativa, agregada de valores que variam de acordo com o percepto. As imagens urbanas despertam percepções dos citadinos, bem como dos visitantes. A diferença se estabelece principalmente nas informações e conteúdos que marcam a rotina desses citadinos, levando-os à agregação de diversos e diferentes significados sobre uma determinada imagem. Imagem que, para o turista, certamente terá outra conotação, visto que ele observa 
uma imagem que se pode chamar de nua, sem informação alguma sobre tal (FERRARA, 1993).

As representações sobre a natureza e o espaço socialmente construído incluem inúmeras figuras de linguagem. Os estudos sobre as cidades também estão impregnados de metáforas, metonímias e sinédoques, revelando que a cidade pode ser interpretada como um texto. A cidade pode ser interpretada, interpretando-se, porém, a história de seu povo, de sua construção, apresentando suas raízes (CORRÊA, 2006).

\section{Considerações Finais}

Como comentário complementar a respeito da importância dos estudos da Nova Geografia Cultural, no que tange à inserção do homem no espaço, não o tornando apenas um elemento, mas parte integrante do processo, faz-se necessário lembrar que nesta nova perspectiva geográfica, as pesquisas contribuem num contexto mais amplo para aprofundamentos teóricos e práticos em vários campos de estudo, mas, sobretudo, nos abordados por este artigo, que correspondem ao campo geográfico e o ao turístico.

Sob esse viés, a chamada Nova Geografia Cultural contribui com seus estudos para o aprofundamento do entendimento do homem no espaço, e um destes tipos de espaço é o turístico, em que o homem tem papel primordial para atuar tanto como turista quanto planejador da atividade, contribuindo com estudos mais aprimorados para a efetivação das atividades desse setor, que visam ressaltar a cultura e a identidade dos destinos turísticos.

Também se faz necessário destacar quão importante foi o viés de estudo que a Nova Geografia Cultural trouxe para os estudos de grupos menos favorecidos, como o dos indígenas e o dos negros, e ainda inclui-se a estes os turistas, e por conseguinte, à atividade turística que, por ainda não ser alinhada a uma ciência específica, discriminadamente tem sentido as consequências da falta de estudos para o desenvolvimento de suas atividades, e que, paulatinamente essa nova vertente da Geografia tem conseguido 
contribuir nesse sentido, amenizando os problemas deste campo de conhecimento e beneficiando ao setor.

Porém, esta vertente denominada "Nova Geografia Cultural" ao mesmo tempo em que contribui para estudos em outros campos, como é o caso do turismo, também sofre preconceitos de outros, como é o caso, de outras escolas geográficas, que não valorizam as abordagens desta vertente geográfica.

Mas, o fundamental nesse processo é persistir nos propósitos indicados pela área de pesquisa desta vertente, contribuindo para os estudos geográficos e de outras áreas menos favorecidas, como o turismo.

Sobre a atividade turística na cidade de Campo Grande, conclui-se por enquanto, que muito há para se pesquisar e contribuir para o aprimoramento do turismo neste espaço urbano, devido a vários fatores, entre os quais se pode citar como prioritário, primeiramente, o fato de que Campo Grande é uma cidade bastante nova, se comparada a outras, como São Paulo, Rio de Janeiro, Salvador e Curitiba, que já conseguiram se consolidar como destinos turísticos.

Diante disto, se esta atividade for aplicada com um planejamento turístico adequado, terá um futuro promissor no setor de Turismo, o qual poderá servir de complemento de renda para a comunidade local, bem como de propagação da cultura local, e como fomento para a atividade turística.

Outro fator a ser considerado é que o aumento de pesquisas no campo geográfico, tendo como objeto de estudo o turismo, no Estado de Mato Grosso do Sul ou até mesmo na própria cidade de Campo Grande, poderá vir a favorecer sobremaneira a atividade turística nesta capital.

Com as questões acima citadas, é possível levar-se em conta que a Nova Geografia Cultural tem em sua curta trajetória contribuído muito para vários campos científicos ou fenomenológicos, como é o caso do turismo, almejandose que este artigo também possa oferecer uma parcela de contribuição para tais estudos. 


\section{Referências}

CASTROGIOVANNI, A. C.. Turismo e ordenação no espaço urbano. In CASTROGIOVANNI, A. C.. (Org.). Turismo urbano. São Paulo: Contexto, 2000. CARLOS, A. F.. Entrevista apresentada ao programa Fantástico (Rede Globo) no dia 25 de março de 2007.

CLAVAL, P.. A Geografia Cultural: o estado da arte. In Manifestações da cultura no espaço. Rio de Janeiro: EdUERJ, 1999.

. O papel da nova geografia cultural na compreensão da ação humana. In ROSENDAHL, Z.; CORRÊA R. L. (Org.) Matrizes da Geografia Cultural. Rio de Janeiro: EdUERJ, 2001.

CORRÊA. R. L.; ROSENDAHL, Z.. O espaço urbano. São Paulo: Ática, 1989.

Introdução à Geografia Cultural. Rio de Janeiro: Bertrand Brasil, 2003.

Paisagem, tempo e cultura. Rio de Janeiro: UERJ, 2004.

CORREAA. R. L.. O urbano e a cultura: alguns estudos. In CORRÊA. R. L.; ROSENDAHL, Z. (Orgs.). Cultura, espaço e o urbano. Rio de Janeiro: UERJ, 2006.

COSGROVE, D.. Geografia Cultural do milênio. In ROSENDAHL, Z.; CORRÊA, R. L. (Orgs.). Manifestações da cultura no espaço. Rio de Janeiro: EdUERJ, 1999.

A Geografia esta em toda parte: Cultura e simbolismo nas paisagens humanas. In CORRÊA. R. L.; ROSENDAHL, Z.. Paisagem, tempo e cultura. Rio de Janeiro: UERJ, 2004.

COSGROVE, D.; JACKSON, P.. Novos rumos da Geografia Cultural. In ROSENDAHL, Z.; CORREAA, R. L. (Org.) Introdução à Geografia Cultural. Rio de Janeiro: EdUERJ, 2003.

CRUZ, R. de C. A.. Introdução à Geografia do Turismo. São Paulo: Roca, 2001.

DAMIANI, A. L.. O lugar e a produção do cotidiano. In CARLOS, A. F. A.. (Org.) Novos caminhos da Geografia. São Paulo: Contexto, 2005.

FERRARA, L. d'A.. O olhar periférico. São Paulo: ESP, 1993.

GOMES, C. C.. Conhecer o lugar e transformar o mundo: o espaço geográfico como possibilidade. In SOUZA, M. A. A. (Org.). Territórios brasileiros: usos e abusos. Campinas: Territorial, 2003.

IBGE.

Disponível

em:

<http://www.ibge.gov.br/cidadesat/painel/painel.php?codmun $=500270>$.

Acesso em: 23 fev. 2011.

SAlGADO, E. M.. Mato Grosso do Sul e a Mesopotâmia do Prosa e Segredo. Campo Grande, 2001.

SANTOS, M. Técnica, espaço, tempo, globalização e meio técnico-científico informacional. São Paulo: Hucitec, 1994.

Metamorfoses do espaço habitado. 5.ed. São Paulo: Hucitec, 1997.

Da totalidade ao lugar. São Paulo: Edusp, 2005.

SAUER, C. O.. The morphology of landscape. University of California Publications. In: Geography, n. 2 (2), 1925. Reproduzido em português em CORREAA. R. L. e ROSENDAHL, Z. (Orgs.) Paisagem, tempo e cultura. Rio de Janeiro: EDUERJ, 1998. 
ISSN: $1982-6125$

SOTTILI, D.. O imaginário do Pantanal no espaço urbano de Campo Grande MS. Dissertação (Mestrado em Geografia), Universidade Federal do Mato Grosso do Sul, Campo Grande, 2005.

Wagner, P.L; Mikesell, M. W.. Os temas da Geografia Cultural. In CORRÊA. R. L.; ROSENDAHL, Z. (Orgs.). Introdução à Geografia Cultural. Rio de Janeiro: Bertrand Brasil, 2003.

YÁZIGI, E.. Turismo e paisagem. São Paulo: Contexto, 2002.

Artigo recebido em janeiro de 2011.

Aprovado para publicação em março de 2011. 